\section{Should Key Performance Indicators for Clinical Services Be Mandatory?}

\section{THE “PRO" SIDE}

Key performance indicators are quantifiable measures that reflect the critical success factors of an organization. Regardless of the indicators selected, each must mirror one or more of the organization's goals. Key performance indicators can be controversial, as they may take into account the competing ideals of various stakeholders. The process of identifying these indicators is complex, since they are seen as quantitative measures of quality. ${ }^{1}$ In this article, I will present the rationale for mandatory key performance indicators for clinical pharmacy services and some of the associated challenges.

\section{Promotion of Improvement through Measurement}

"If you're not keeping score, you're only practising, not playing." Attributed to US football coaching legend Vince Lombardi, this statement is arguably applicable to performance measurement, where key performance indicators are a means of "keeping score" in the business of health care.

Without the requirement to comply with client-focused accreditation standards and performance measures, it is unlikely that various quality improvement and patient safety agendas would have progressed as substantially as they have over the past several years. ${ }^{2}$ For example, by measuring key performance indicators of evidence-based care for patients with acute myocardial infarction (e.g., initiation of timely reperfusion; prescription of acetylsalicylic acid, angiotensin-converting enzyme inhibitors, ß-blockers, and statins upon discharge from hospital; and interventions for smoking cessation) we have achieved a steady decline in rates of in-hospital death and readmission over the past several years. ${ }^{2-5}$ Furthermore, facilities that have voluntarily adopted protocols and measures advocated by organizations such as the Canadian Patient Safety Institute have reported improvements in timely administration and discontinuation of prophylactic antibiotics with the overall goal of reducing the frequency of surgical site infection and death.,

Other benefits of implementing a system to measure clientfocused key performance indicators for clinical pharmacy services include enhanced transparency and accountability. These themes have figured prominently in the transportation industry, ${ }^{7}$ financial institutions, ${ }^{8}$ and government agencies ${ }^{9}$ in recent years. Mandatory reporting regimes create transparency, which can lead to better performance in those areas most crucial to stakeholders and to society in general. ${ }^{10}$

In today's climate of competing priorities and limited resources, if a health care system is not effective, then the quality of patient care suffers. Furthermore, if the health care system is not efficient, it contributes to unwarranted escalation in the cost of care. Hospital pharmacy managers are charged with maintaining both the effectiveness and the efficiency of their resources. ${ }^{11}$ Admittedly, the mere presence of key performance indicators may not guarantee that a clinical pharmacy service is effective or efficient. However, just as measurement of the quality of process and clinical outcomes has resulted in improvements in outcomes and the culture of patient safety, as described above, it is probable that instituting key performance indicators for clinical pharmacy services will elevate our professional accountability and transparency, as well as the quality of care.

\section{Challenges of Adopting Clinical Key Performance Indicators}

Compared with pharmacy distribution activities, clinical activities have been considered difficult, if not impossible, to measure. Even so, the time that a pharmacist spends in clinical activities often results in substantial savings for the hospital, in terms of reductions in drug costs and improvements in patient outcomes. ${ }^{11}$ A pharmacist who provides direct patient care as a member of a multidisciplinary team can help to identify medication-related issues much earlier in the medication-use process, which can result in avoidance or reduction of drug costs, reductions in length of stay or readmission rates, and decreases in morbidity and mortality. ${ }^{12-14}$ Unfortunately, such benefits are not measured by current productivity monitoring systems. ${ }^{11}$ There is no established national or international consensus on what constitutes a key performance indicator for clinical pharmacy services. ${ }^{15}$ The pharmacy profession needs to better define minimum standards for its clinical services to permit comparisons within and between organizations. It also needs to work with software vendors to develop meaningful systems that will automate the collection and reporting of key performance indicators. ${ }^{16}$ Although many hospitals have resisted the implementation of standardized improvement measures for clinical care, seeing them as too strict or impossible to attain, early adopters of these measurement programs have witnessed significant improvements in performance over the past decade. ${ }^{2}$ Many of these measures provide tight, evidence-based links between process performance and patient outcomes. ${ }^{2}$ Pharmacies that successfully develop and implement key performance indicators for their clinical services may be seen as innovators or early adopters of this measurement process, consistent with other services and programs in their organization.

Another challenge will be choosing among key performance indicators for structures, processes, or outcomes. A few core activities constitute most of pharmacy's total clinical workload: obtaining and reconciling medication histories; providing medication counselling; assessing, monitoring, and adjusting 
medication therapy regimens, including taking into account allergies and intolerances to medication; participating in patient care rounds; and providing pharmacokinetic and other consultations. ${ }^{16}$ Monitoring such measures may give management a good perspective on pharmacy's effectiveness and efficiency. However, we should also consider key performance indicators that reflect patient outcomes. Such measures are already collected by many institutions (e.g., rates of acute myocardial infarction, heart failure, surgical site infection, venous thromboembolism, and ventilator-associated pneumonia), and our pharmacy teams currently contribute to these data. These approaches offer opportunities to benchmark against external organizations using indicators in the Hospital Pharmacy in Canada Report ${ }^{17}$ or the CSHP 2015 initiative. ${ }^{18}$ More importantly, properly selected key performance indicators allow internal benchmarking to monitor progress of a program or service over time. ${ }^{15}$

Despite the challenges of implementing key performance indicators for clinical services, we must keep in mind that if pharmacy lingers too long in meeting these challenges, other stakeholders such as departments or ministries of health may establish the indicators for us, perhaps even without our input, leaving us to strive for inappropriate targets. We can demonstrate our leadership in this respect by proactively initiating the dialogue about measuring the performance of pharmacy services within our organizations. I believe that establishing a requirement for key performance indicators would enhance pharmacists' positions as accountable and transparent stewards of health care resources.

\section{Conclusions}

The key performance indicators of clinical pharmacy services should be made mandatory, with the ultimate goal of improving the quality of health care in our organizations. Selected key performance indicators should encompass a cross-section of each pharmacy department's structures, processes, and outcomes in contributing to safe and effective medication use. Pharmacy leaders should begin by initiating dialogue with internal stakeholders about which indicators will align with overall measures of quality and safety for the organization. Just as accreditation measures have matured over the past decade, the profession of pharmacy will determine over time which key performance indicators best correlate with optimal outcomes for patients and other stakeholders.

\section{References}

1. MIbrahim JE. Performance indicators from all perspectives [editorial]. Int J Qual Health Care 2001;13(6):431-432.

2. Chassin MR, Loeb JM, Schmaltz SP, Wachter RM. Accountability measures - using measurement to promote quality improvement. $N$ Engl J Med 2010;363(7):683-688.

3. Goodman SG, Huang W, Yan AT, Budaj A, Kennelly M, Gore JM, et al.; Expanded Global Registry of Acute Coronary Events (GRACE2) Investigators. The expanded Global Registry of Acute Coronary Events: baseline characteristics, management practices, and hospital outcomes of patients with acute coronary syndromes. Am Heart J 2009;158(2):193-201.e1-e5.

4. Acute myocardial infarction (AMI). In: Safer Healthcare Now! [website]. Edmonton (AB): Canadian Patient Safety Institute; [cited 2010 Nov]. Available from: www.saferhealthcarenow.ca/EN/Interventions/ami/Pages/ default.aspx
5. Cyr C. Improved care for acute myocardial infarction. $N B$ Heart Cent Newsl 2007 Spring [cited 2010 Nov]. Available from: www.ahsc.health.nb.ca/Programs/NBHC/heartbeat/NBHC\%20Safer\% 20Health\%20Care\%20Now_english.pdf

6. Surgical site infection (SSI). In: Safer Healthcare Now! [website]. Edmonton (AB): Canadian Patient Safety Institute; [cited 2010 Nov]. Available from: www.saferhealthcarenow.ca/EN/Interventions/SSI/Pages/default.aspx

7. GAIN Working Group B (Analytical Methods and Tools). Role of analytical tools in airline flight safety management systems. 2nd ed. Alexandria (VA): Global Aviation Information Network; 2004 Sep [cited 2010 Nov]. Available from: http://flightsafety.org/files/analytical_tools_ in_safety.pdf

8. Empowering and protecting consumers of financial services. In: Reforming Canada's financial services sector - a framework for the future. Ottawa (ON): Finance Canada; 2008 Oct 23 [cited 2010 Nov]. Available from: www.fin.gc.ca/finserv/docs/finserv4-eng.asp

9. Proactive disclosure. Ottawa (ON): Treasury Board of Canada Secretariat; 2006 May 31 [cited 2010 Nov]. Available from: www.tbs-sct.gc.ca/pddp/index-eng.asp

10. Lydenberg S, Rogers J, Wood D. Transparency to performance. Cambridge (MA): Harvard Kennedy School of Government; 2010.

11. Barnum DT, Shields KL, Walton SM, Schumock GT. Improving the efficiency of distributive and clinical services in hospital pharmacy. J Med Syst 2009. Epub ahead of print 2009 Jul 14. DOI 10.1007/s10916-009-9341-2.

12. Bond CA, Raehl CL. Clinical pharmacy services, pharmacy staffing, and hospital mortality rates. Pharmacotherapy 2007;27(4):481-493.

13. Kaboli PJ, Hoth AR, McClimon BJ, Schnipper JL. Clinical pharmacists and inpatient medical care: a systematic review. Arch Intern Med 2006;166(9):955-964.

14. Makowsky MJ, Koshman SL, Midodzi WK, Tsuyuki RT. Capturing outcomes of clinical activities performed by a rounding pharmacist practicing in a team environment: the COLLABORATE study. Med Care 2009;47(6):642-50.

15. Ng J, Harrison J. Key performance indicators for clinical pharmacy services in New Zealand public hospitals: stakeholder perspectives. $J$ Pharm Health Serv Res 2010;1(2):75-84.

16. Rough SS, McDaniel M, Rinehart JR. Effective use of workload and productivity monitoring tools in health-system pharmacy, part 2. Am J Health Syst Pharm 2010;67(5):380-388.

17. Babich M, Bussières JF, Hall KW, Harding J, Johnson N, Lefebvre P, et al., editors. Hospital pharmacy in Canada report 2007/2008. Eli Lilly; 2008 [cited 2010 Nov]. Available from: www.lillyhospitalsurvey.ca/hpc2/ content/rep_2008_toc.asp

18. CSHP 2015 [website]. Ottawa (ON): Canadian Society of Hospital Pharmacists; 2010 [cited 2010 Nov]. Available from www.cshp.ca/programs/ $\operatorname{csh} 2015 /$

Douglas Doucette, RPh, BSc(Pharm), PharmD, FCSHP

Regional Pharmacy Clinical Manager

Horizon Health Network

Moncton, New Brunswick

\section{THE "CON" SIDE}

A key performance indicator is a measure focusing on an aspect of an organization's performance that is deemed critical to its success. ${ }^{1}$ The organization must first establish its strategic and operational goals and then choose key performance indicators that best reflect those goals. As a pharmacy director, I believe in the value of key performance indicators as powerful tools that provide the relevant information needed to lead the organization in a strategic direction. However, I also recognize several barriers that must be overcome before key performance indicators for clinical pharmacy can become mandatory. 
A standard approach to developing a key performance indicator involves applying the "SMART" criteria. According to this process, the key performance indicator must be specific, measurable, attainable, relevant, and timely. ${ }^{2}$ For the purposes of this discussion, I will focus on only two of these criteriarelevance and measurability - to help build my argument against making clinical key performance indicators mandatory.

The first aspect I would like to consider is the relevance of a clinical key performance indicator. The American College of Clinical Pharmacy has stated that "clinical pharmacists provide patient care that optimizes medication therapy". ${ }^{3}$ Given this definition, a relevant key performance indicator in clinical pharmacy would be one that highlights those therapeutic activities of the clinical pharmacist that matter to both the patient and the organization. Currently, there are no universally accepted, standard key performance indicators in clinical pharmacy to indicate the clinical pharmacist's contribution to patient care. ${ }^{4.5}$ The number of clinical interventions per pharmacist is often cited as a clinical key performance indicator, ${ }^{4}$ but this measure may hold more value for the pharmacy manager than for someone outside the department.

The issue of relevance to the organization can be viewed in different ways, depending upon who is defining "relevance". $\mathrm{Ng}$ and Harrison, in their recent observational study, highlighted this point. ${ }^{6}$ The authors constructed a survey about key performance indicators of the clinical pharmacist's contribution to patient care, based on the current literature. They administered the survey to key stakeholders (i.e., chief pharmacist, chief medical officer, director of nursing, quality and risk manager, and senior management team) in hospitals across New Zealand. The respondents were asked to rate the relevance of each indicator. $\mathrm{Ng}$ and Harrison found variations in the ratings among the key stakeholders, although the differences were not statistically significant. The article also highlighted the lack of standardized key performance indicators as a barrier to identifying clinical indicators relevant to pharmacists' contribution to patient care. In the absence of standardized clinical indicators, a national standard needs to be developed. Any proposed clinical key performance indicators should incorporate the work of Bond and Raehl, who have highlighted specific functions of the clinical pharmacist that have been shown to affect patient care (in terms of total cost of care, cost of drugs, length of stay, and medication errors). Once these types of clinical indicators are developed and agreed upon within the pharmacy, they can then be presented to the key stakeholders to ascertain their fit within the organization as a whole.

The second aspect I would like to consider is the measurability of key performance indicators. Indicators reflecting the distribution side of pharmacy services can often be obtained by capturing relevant data from the pharmacy information system. Capturing the data required to report clinical indicators is more difficult and time-consuming. Reporting of data for clinical indicators can be done either retrospectively, through chart review by assigned pharmacy staff, or prospectively, by having the clinical pharmacist report his or her own daily patient care activities. This is done manually on workload activity forms or with handheld electronic devices. ${ }^{8,9}$ Both methods are labour- and resourceintensive, and each represents an additional daily task for pharmacy personnel. Resources to record and collect these data may be scarce, in both financial and human terms. Sites that are short of staff or that do not have the resources to pay for extra staff may be unable to readily collect the data. If reporting of key performance indicators were to become mandatory, a site faced with scarce resources might be forced to channel existing resources into recording and collecting data at the expense of providing direct patient care. One possible solution to this dilemma lies in the patient chart. As part of the normal pattern of work, pharmacists document their recommendations directly in the patient chart; as such, the health records department could help in retrieving and reporting the necessary data. The cost for this type of service should not be prohibitive. ${ }^{10}$ However, as has been seen with the coding of medical diagnoses by nonmedical personnel, this method can be expected to have limitations.

As health authorities deal with limited resources and increased scrutiny from government through pay-forperformance initiatives, senior management will be looking for the value that clinical pharmacists provide. I think that key performance indicators will come to be used as tools for assessing this value. Before clinical key performance indicators become mandatory, however, attention must be paid to developing relevant, standardized indicators that highlight the clinical pharmacist's contribution to patient care in a resource-friendly manner.

\section{References}

1. Wyatt J. Scorecards, dashboards, and KPIs keys to integrated performance measurement. Healthc Financ Manage 2004;58(2):76-80

2. Hursman A. Measure what matters-seven strategies of selecting relevant key performance indicators. Inform Manage Mag 2010 Jul-Aug;:1-2.

3. The definition of clinical pharmacy. Pharmacotherapy 2008;28(6): 816-817.

4. Rough SS, McDaniel M, Rinehart JR. Effective use of workload and productivity monitoring tools in health-system pharmacy, part $2 . \mathrm{Am} \mathrm{J}$ Health Syst Pharm 2010;67(5):380-388.

5. Gupta S, Wojtynek JE, Walton SM, Botticelli JT, Shields KL, Quad JE, et al. Monitoring of pharmacy staffing, workload and productivity in community hospitals. Am J Health Syst Pharm 2006;63(18):1728-1734.

6. Ng J, Harrison J. Key performance indicators for clinical pharmacy services in New Zealand public hospitals: stakeholder perspectives.J Pharm Health Serv Res 2010;1(2):75-84.

7. Bond CA, Raehl CL. Clinical pharmacy services, pharmacy staffing, and hospital mortality rates. Pharmacotherapy 2007;27(4):481-493.

8. Patel RJ, Lyman AE Jr, Clark DR, Hartman TJ, Chester EA, Kicklighter CE. Personal digital assistants for documenting primary care clinical pharmacy services in a health maintenance organization. Am J Health Syst Pharm 2006;63(3):258-261.

9. Collins MF. Measuring performance indicators in clinical pharmacy services with a personal digital assistant. Am J Health Syst Pharm 2004; 61(5):498-501.

10. Gordon, W, Malyuk D, Taki J. Use of health-record abstracting to document pharmaceutical care activities. Can J Hosp Pharm 2000;53(3):199-205.

Bruce Millin, BSc(Pharm), ACPR

Regional Administration

Lower Mainland Pharmacy Services

Langley, British Columbia 